\title{
Sleeping pattern of horses in selected local horse stables in Malaysia
}

\begin{abstract}
Horses typically spend between from 4 to 15 hours a day in standing rest and anywhere from minutes to several hours lying down. Horses that have less sleep due to prolonged activities will result in health deterioration and poor welfare. From the literature search and from the authors' knowledge, the study on the sleeping patterns of domesticated horses in stable management in the tropics has not yet been explored. Thus, the aim of this study was to understand the sleeping patterns of selected local stabled horses in Malaysia. This study was conducted in 3 different stables around Klang Valley, Malaysia. Five healthy adult gelding Thoroughbred horses with body condition score of 3 out of 5 were selected randomly from each stable. The horses experienced the same daily activities and exercised for approximately 4 hours every day where they were used for riding activity. An observational cohort study method was used in this study. Each horse's sleeping patterns were observed for 72 hours. The time frame was divided into 12 hours a day for 6 days, continuously. In the present study, horses tended to sleep only during the night. The stable horses spent about $57.00 \pm 25.00$ $\mathrm{min} / 24 \mathrm{~h}$ in sternal recumbency; $8.00 \pm 6.00 \mathrm{~min} / 24$ hours in lateral recumbency; and $3.40 \pm$ 0.70 minutes in each stay apparatus position before shifting weight to the other hindlimb. The implication of these findings will allow equine practitioners to understand the different sleeping patterns of horses to maintain the horses' welfare and performance.
\end{abstract}

Keyword: Horses; Tropic; Stable; Sleeping patterns; Recumbency; Sleeping period 